Journal of Computer Science and Technology Studies (JCSTS))

ISSN: $2709-104 \mathrm{X}$

DOI: $10.32996 /$ jcsts

Journal Homepage: www.al-kindipublisher.com/index.php/jcsts

\title{
The Success of the Electric Vehicle and Simulation of an Electric Vehicle Navigation System with PWM Control
}

\author{
Md. Fahad Hasan ${ }^{1}$ \&(D), Md. Bulbul Ahammed ${ }^{2}$ (D), Kalyan Mondol ${ }^{3}$ (D), Sadia Sultana ${ }^{4}$ (ID) and Anirban \\ Sarkar 5 (D) $\triangle$ \\ ${ }^{1}$ Department of Electrical \& Electronic Engineering, American International University-Bangladesh \\ ${ }^{234}$ Department of Electrical \& Electronics Engineering, The International University of Scholars, Dhaka, Bangladesh
}

$\triangle$ Corresponding Author: Anirban Sarkar, E-mail: anirban@ius.edu.bd

\section{ARTICLE INFORMATION ABSTRACT}

Received: April 08, 2021

Accepted: June 14, 2021

Volume: 3

Issue: 2

DOI: $10.32996 /$ jcsts.2021.3.2.3

\section{KEYWORDS}

Electric Vehicle (EV), Arduino

Mega, OLED display, Diesel Engine,

Proteus, PWM
This paper gives an outline of ongoing work on electric vehicles in the area. The paper depicts the turn of events, and examination of various pieces of the principal segments of battery innovation, engine, forward, invert, start-stop, and slowing down are inspected. The paper examines the benefits of diesel motors and electric motors. Here are a few depictions of how the dark smoke from a diesel motor can harm our bodies. The paper, at last, appears as models of some electric vehicles finishing of administrative work.

\section{Introduction}

Electric vehicles (EVs) depend on electrical conductivity frameworks. No interior fuel motor is utilized. All energy and force depend on electrical energy as the source. The principle advantage is that this medium makes high productivity of force transformation through the proposed strategy for an electric engine. As of late, there has been a lot of innovative work in both scholarly and mechanical fields and a lot of accomplishment exists. This vehicle is accessible in various nations as a business vehicle. Numerous nations have given motivating forces to clients through lower duty or assessment exceptions, free stopping, and free charging offices and they are utilizing it with more achievement and reserve funds. It is fairly simple to construct electric vehicle structures. One of the key segments is the electrical part. Figure 1 shows the design.

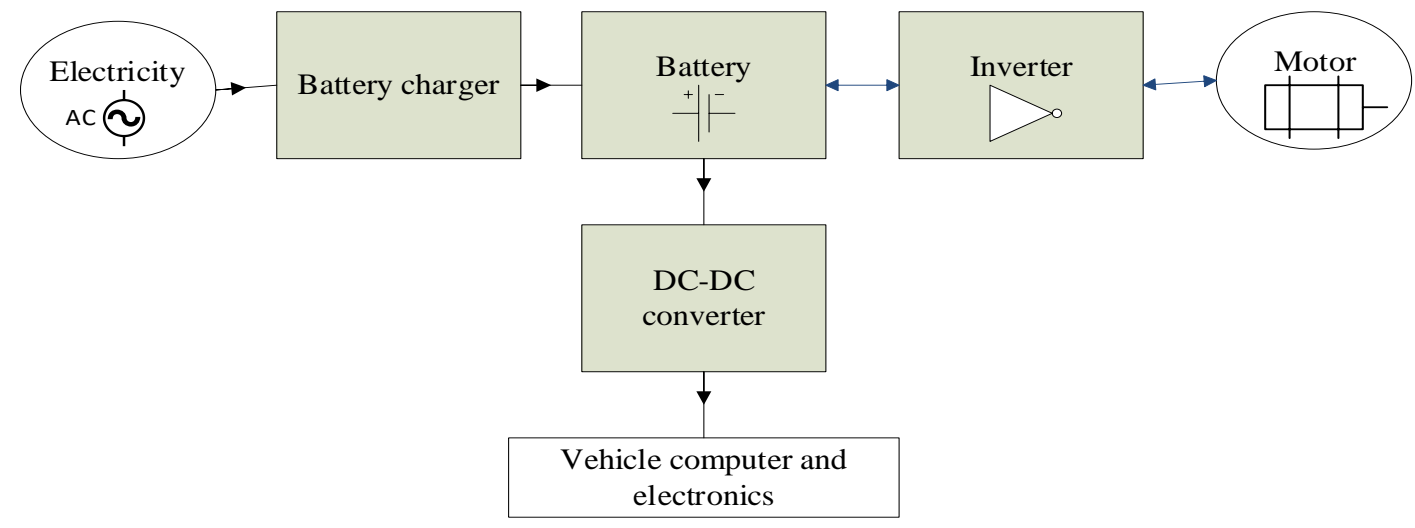

Figure 01: Key Component of Electrical Vehicle

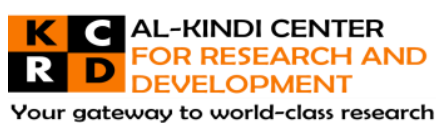

\begin{tabular}{l|l|l}
$\mathbf{K}$ & $\mathbf{C}$ & AL-KINDI CENTER \\
$\mathbf{R}$ & $\mathbf{D}$ & FOR RESEARCH AND \\
DEVELOPMENT
\end{tabular} Your gateway to world-class research

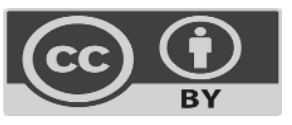

Published by Al-Kindi Center for Research and Development. Copyright (c) the author(s). This open access article is distributed under a Creative Commons Attribution (CC-BY) 4.0 license 


\section{Literature Review}

The battery of an electric vehicle is the fundamental energy saver. The battery charger is a procedure used to change power from mains over to batteries(Yoo et al., 2008). The voltage of the battery is DC and I turn around the switch-mode signal through the force electronic inverter to run the engine. Other electronic segments in a vehicle can be provided to the battery through a DCDC converter that brings down the voltage from the battery pack to a voltage of 5V-20V(Cheng, 2009). There would be an abundant supply from and different parts would be harmed.

The utilization of electric vehicles has prompted a decrease in air contamination on the planet today. Policymakers raised fundamental issues on carbon-based discharges and ozone harming substance emanations (GHGs) have been raised since 1998 when the Kyoto Convention was ordered. Transport 98\% of fossil-subordinate oil that is seriously influenced by energy change assets and electric vehicles (EVs) are elective fuel vehicles (AFVs) that can diminish GHG discharges (Hacker et al., 2009). AFVs have been executing financial approaches to help the green vehicle and electric vehicle (EVs) market, which is now being carried out in different nations to help human progress move all the more easily. A few researchers proposed a system that will automatically identify vehicles using live streaming video, and the identified visuals will be utilized to detect traffic violations(Studies, 2020). The electric vehicle EV is enormously encouraging in the future as it can lessen petroleum utilization and GHG discharges by $30 \%$ to half without the need to change vehicle class and gear(Romm, 2006). In any case, more boundless utilization of electric vehicles is as yet hampered by restricted battery limit, which permits cruising ranges somewhere in the range of 150 and 200 kilometers(Artmeier et al., 2010). A new study domain on the Ultra-Wideband (UWB) system may be to expand the vehicle's range of control and overcome its interference with GPS, according to a few researcher's studies(Sarkar et al., 2018). Using a much efficient PWM control technique they developed an electric vehicle where a brushless DC motor is used to power the wheels(Rajan \& Raju, 2019).

The previously mentioned systems may not think about execution in various environments. That review needs execution investigation of motor-driven vehicles and electric vehicles. Besides, a total perception framework has been precluded in the above investigation. Electric vehicles are generally equivalent to motor-driven vehicles. Where various sorts of fuel are utilized for motor-driven vehicles yet on account of electric vehicles just battery charge is utilized which is harmless to the ecosystem and efficient. In this article, the strategy and engineering of the framework are examined and fundamentally talk about the examination of the outcomes.

\section{Methodology}

The essential reasoning for electric vehicles is represented in Figure 2 by a straightforward savvy rationale stream diagram direction model. The square graph is essentially separated into two sections. Electrical parts and programming parts. In the segment on mechanical parts, plan ideas, vehicle structures are portrayed. Circuit determination and circuit gathering are the principal centers in the electrical part. In the product area, techniques and programming as per exchanging are portrayed exhaustively. The combination component of programming and electrical parts is coordinated by the aftereffects of tests, circuit tests, and program tests. At last, the test and critical thinking parts are tried for the ultimate choice.

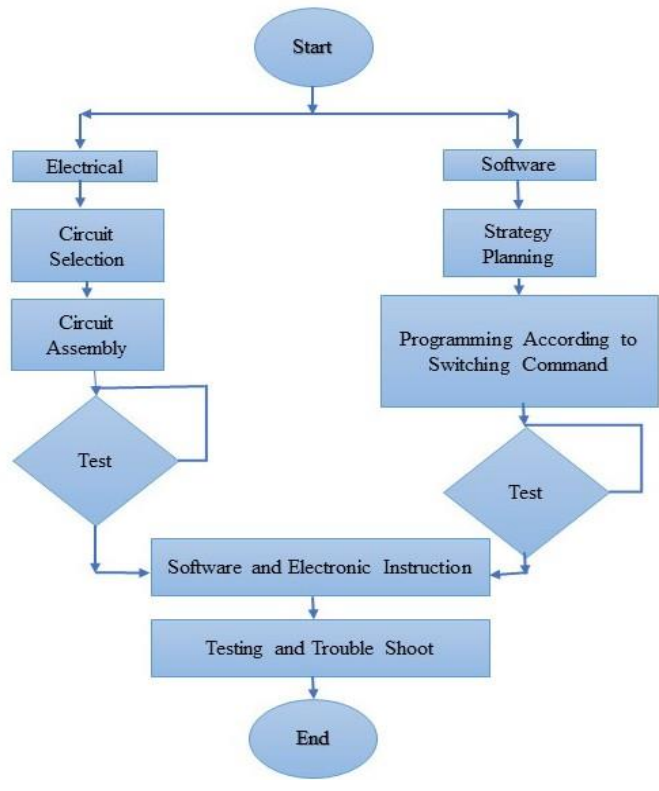

Figure 02: Basic Design of Electrical Car. 
The PCB plan in Figure 3 shows how the proposed electric vehicle will function. The base is made of Arduino Mega, DC engine, switch, and display.

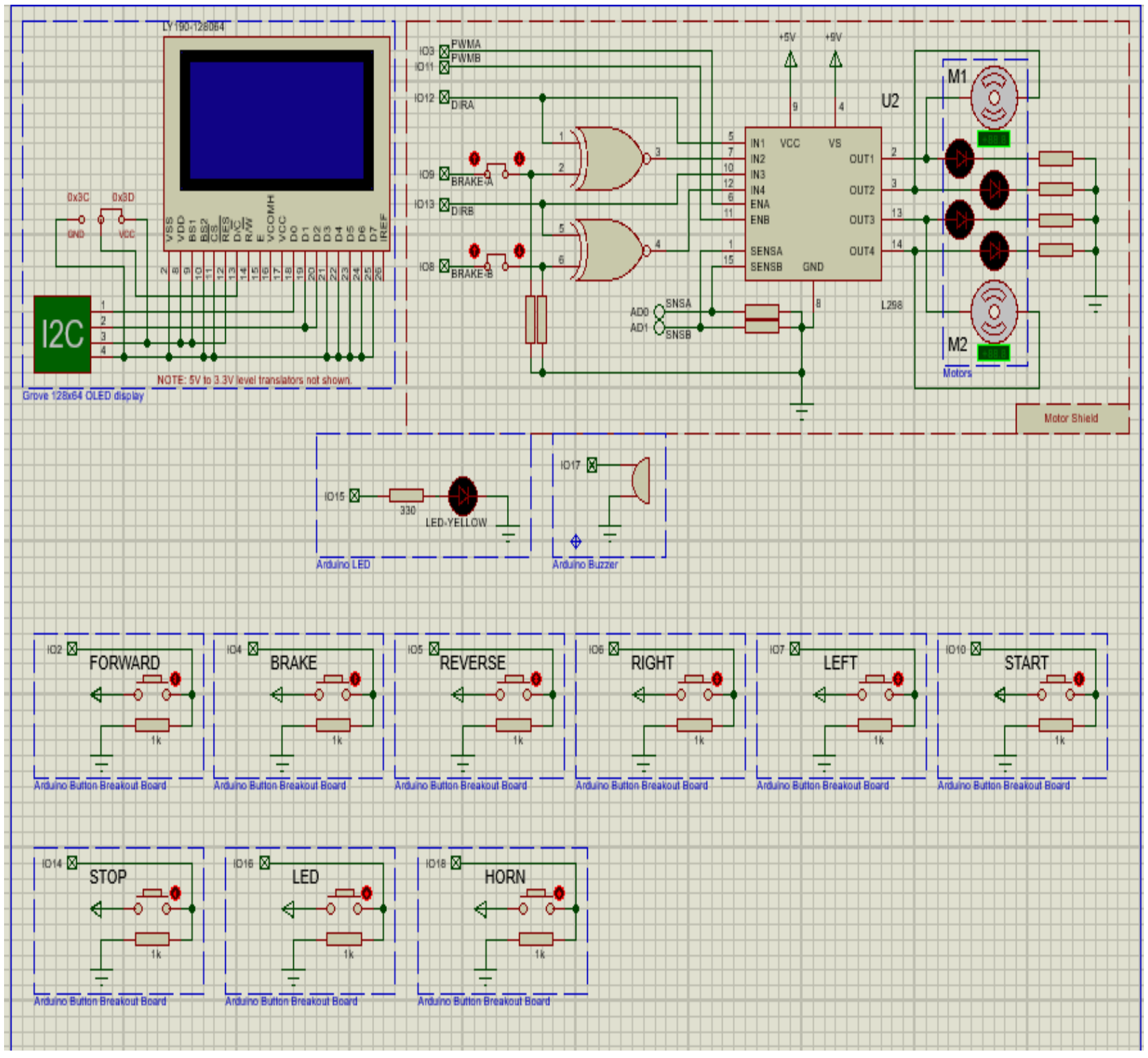

Figure 03: Simulation Model of Electric Car.

\subsection{Simulation Implementation}

A. Main Function: This recreation was finished utilizing Proteus. Where the schematic chart is made through a flowchart of the visual plan. This flowchart has the primary capacity. Which has set up and circle works inside. In the arrangement of the fundamental capacity, the principal engine 1 and engine 2 stop work outline has been utilized. Then, at that point, a capacity is allocated, where forward move state, switch move state, brake, power on, turn speed, speed, right move, message, left move, horn, Driven, GPS tracks are appointed. "Welcome ready" is shown as a presentation message in the fundamental capacity, this message will show when the force is turned on. 

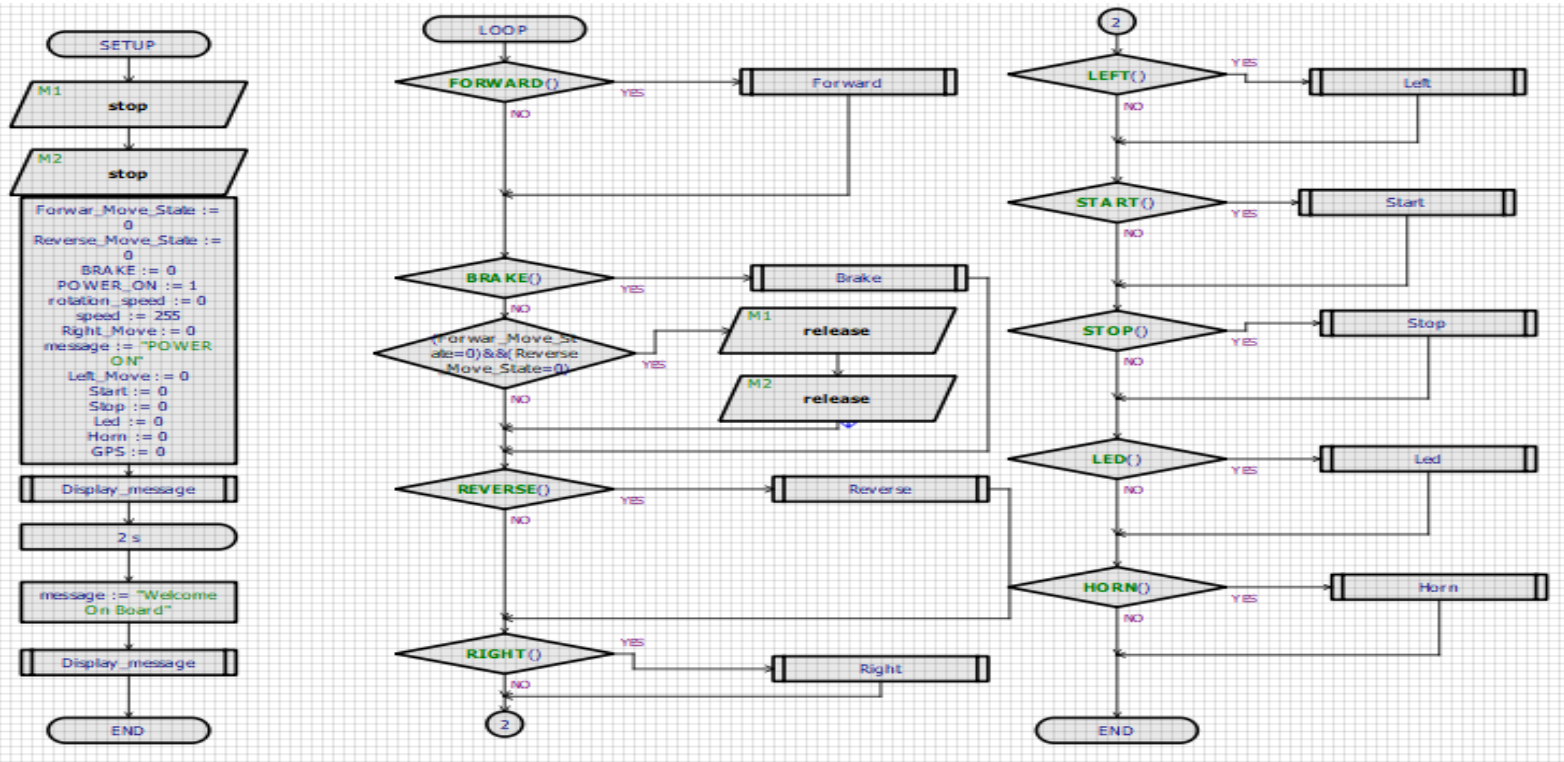

Figure 04: Main function Flowchart is a visual designer.

We have effectively said that first, there are two capacities, one of which is a circle. In the schematic chart, one switch is utilized for each errand. Which switches will work when a client needs to utilize his necessities. For instance, assuming the transporter needs to go ahead, then at that point, on the off chance that you press the forward referenced switch, the vehicle will keep on going ahead. In this manner, each switch can do whatever it might feel like doing. The call work is utilized alongside the circle graph in the switch gular work. The consider capacity of the switch for which the capacity has been chosen so it plays out the assignments effectively with regards to the primary capacity.

B. Display Message: A display has been utilized in the vehicle to survey whether each capacity is working appropriately. The schematic graph utilizes a $128 \times 64$ OLED show. Any place the switch will be utilized, the message of that switch will be shown on the showcase that this thing is on at this point. A different flowchart is utilized for the showcase work, where an unmistakable presentation is utilized as the primary capacity. Then, at that point set text tone is utilized. White has been utilized as the shading here. Any tone can be utilized. Anybody can utilize Framework Board or RGB assuming they need it. Then, at that point, the text size and cursor capacities are utilized, which clears the text and keeps the text dimension right.

C.
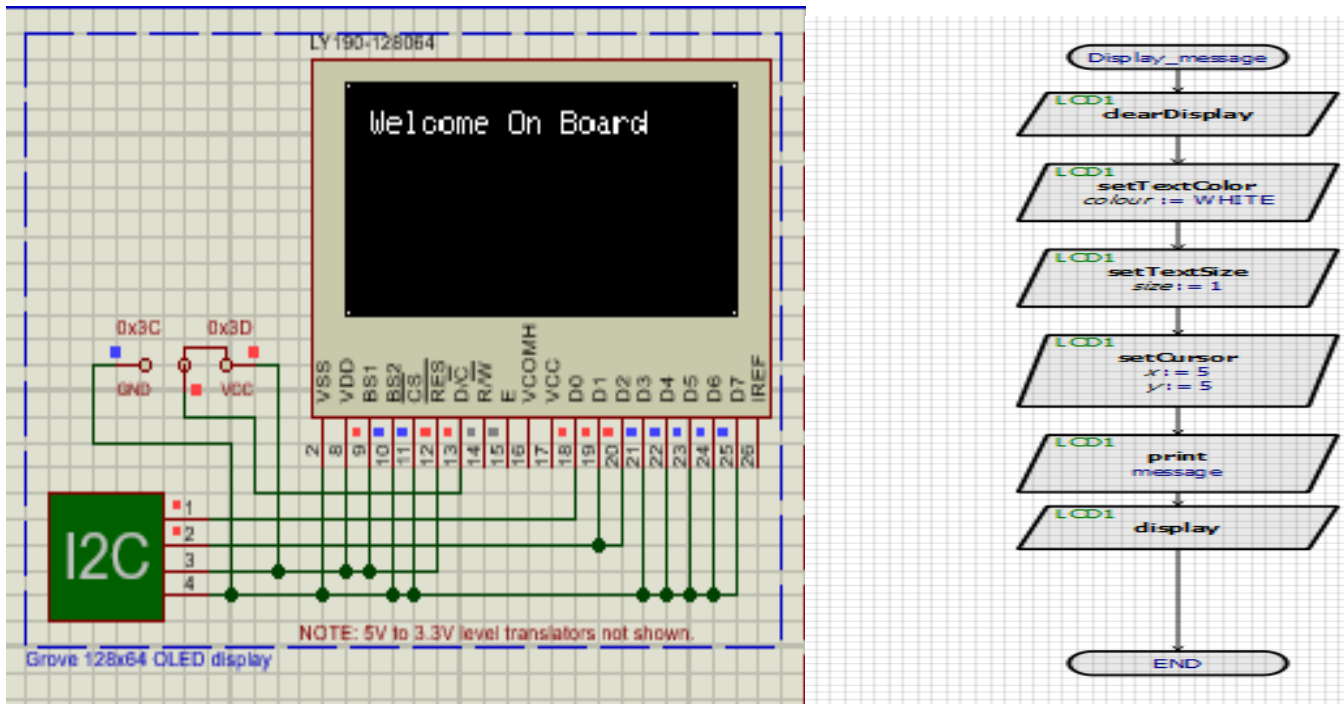

Figure 05: OLED display and display function. 
D. Start: The beginning capacity is utilized to begin the vehicle. There is a beginning switch in the schematic graph. At the point when this switch is turned on, the motor will be on. In Flowchart, we initially relegate start, forward, converse, and brake capacities. Here every one of the capacities aside from the beginning capacity is off. At the point when the switch is squeezed, the presentation message says "Engine ready to start". Presently Pins 6 and 9 of Arduino Super will be doled out, where computerized right is valid. Then, at that point, a defer will be utilized in the flowchart, the deferral is 4 seconds. Following 4 seconds, Pins 8 and 9 of Arduino Uber will be relegated once more, where the computerized right is bogus. Then, at that point, the showcasing message will show "Engine start" which we can find in Figure 6 beneath.

E.
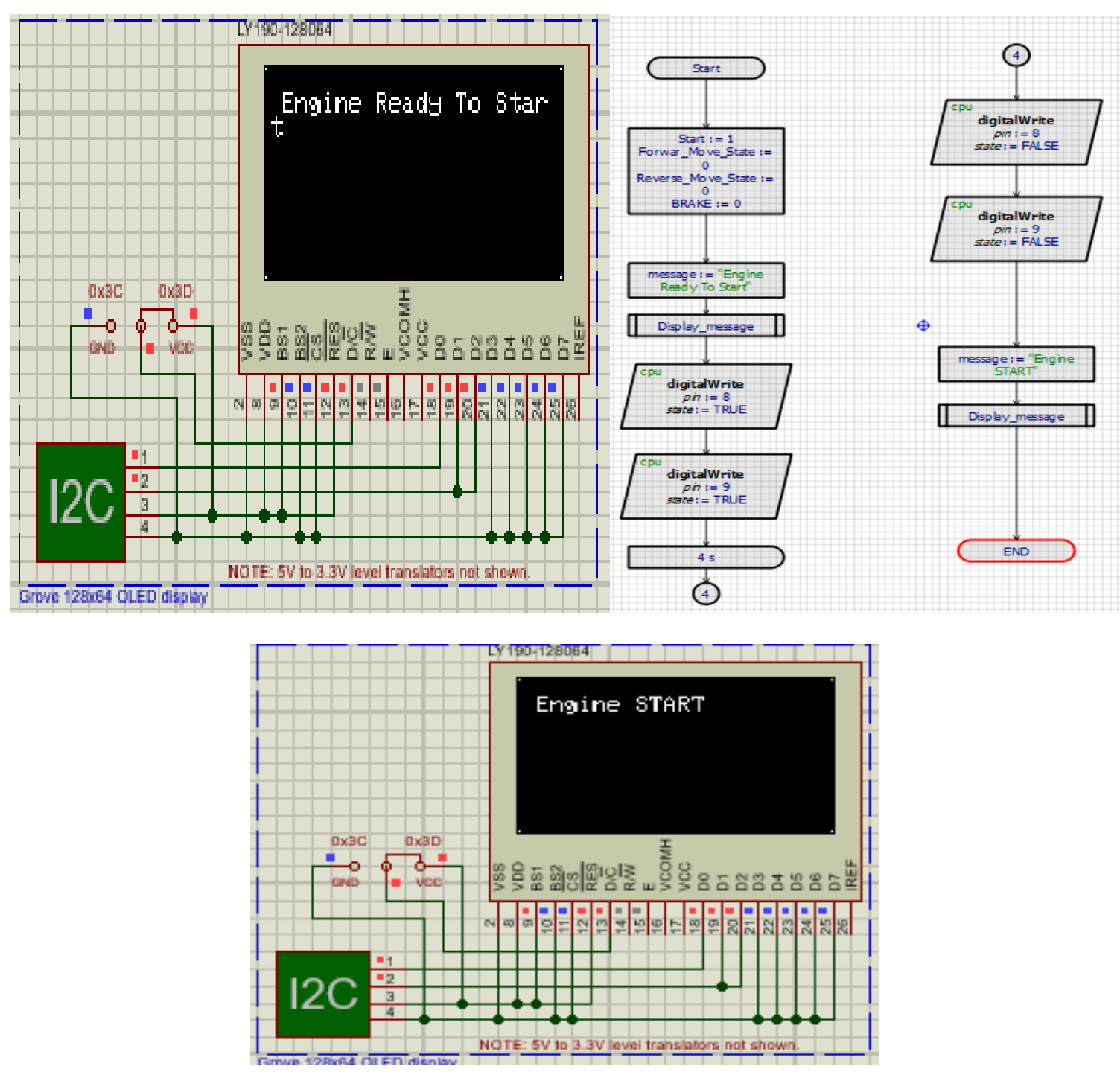

Figure 06: Start Function.

F. Stop: The stop-work is utilized to prevent the vehicle from running and stop the motor. There is a stop switch in the schematic outline. At the point when this switch is turned on, the motor will wind down. In the flowchart, we initially appoint stop, forward, converse, and brake works similarly as the beginning capacity. Here every one of the capacities except for the stop-work is off. Pins 8 and 9 of the Arduino Uber will presently be relegated in the stream diagram, where the advanced right is valid. Then, at that point a defer will be utilized in the flowchart. The postponement is 4 seconds. Following 4 seconds, Pins 8 and 9 of Arduino Super will be doled out once more, where the advanced right is bogus. Then, at that point the presentation message will show "Engine Stop" which we can find in Figure 7 underneath. 

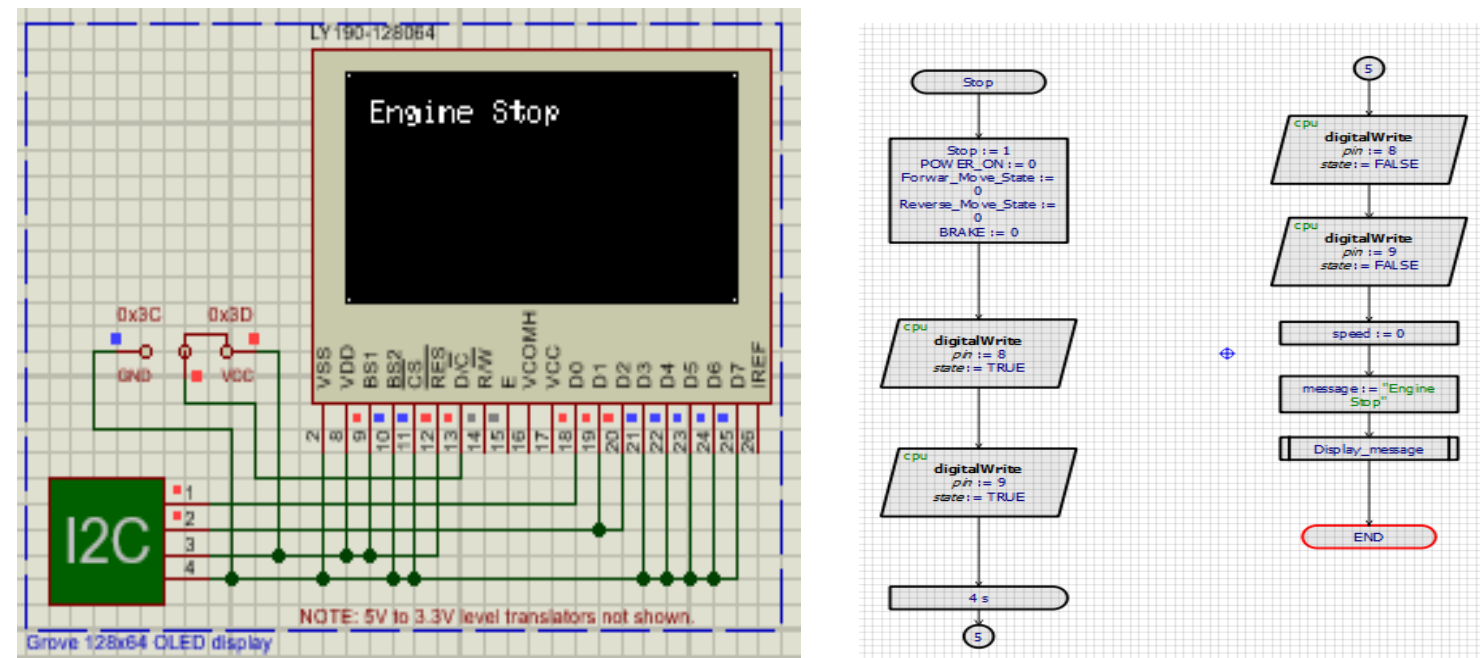

Figure 07: Stop Function.

G. Forward: This time a forward work has been made in the vehicle to run forward. Initial, a capacity is doled out, within which opposite and brake capacities are off however, pivot speed and forward speed are on. Pivot speed can be taken from 0 to 255 here. We have utilized the greatest speed here. Then, at that point, we dole out the run capacity of engine 1 and engine 2 where heading forward and speed revolution are showing speed. At the point when we divert on the forward change from the schematic chart, our showcase message will show the pushing ahead and how quick it is running. Since we have utilized the most extreme speed, it will show 255 here, as displayed in Figure 8 beneath.
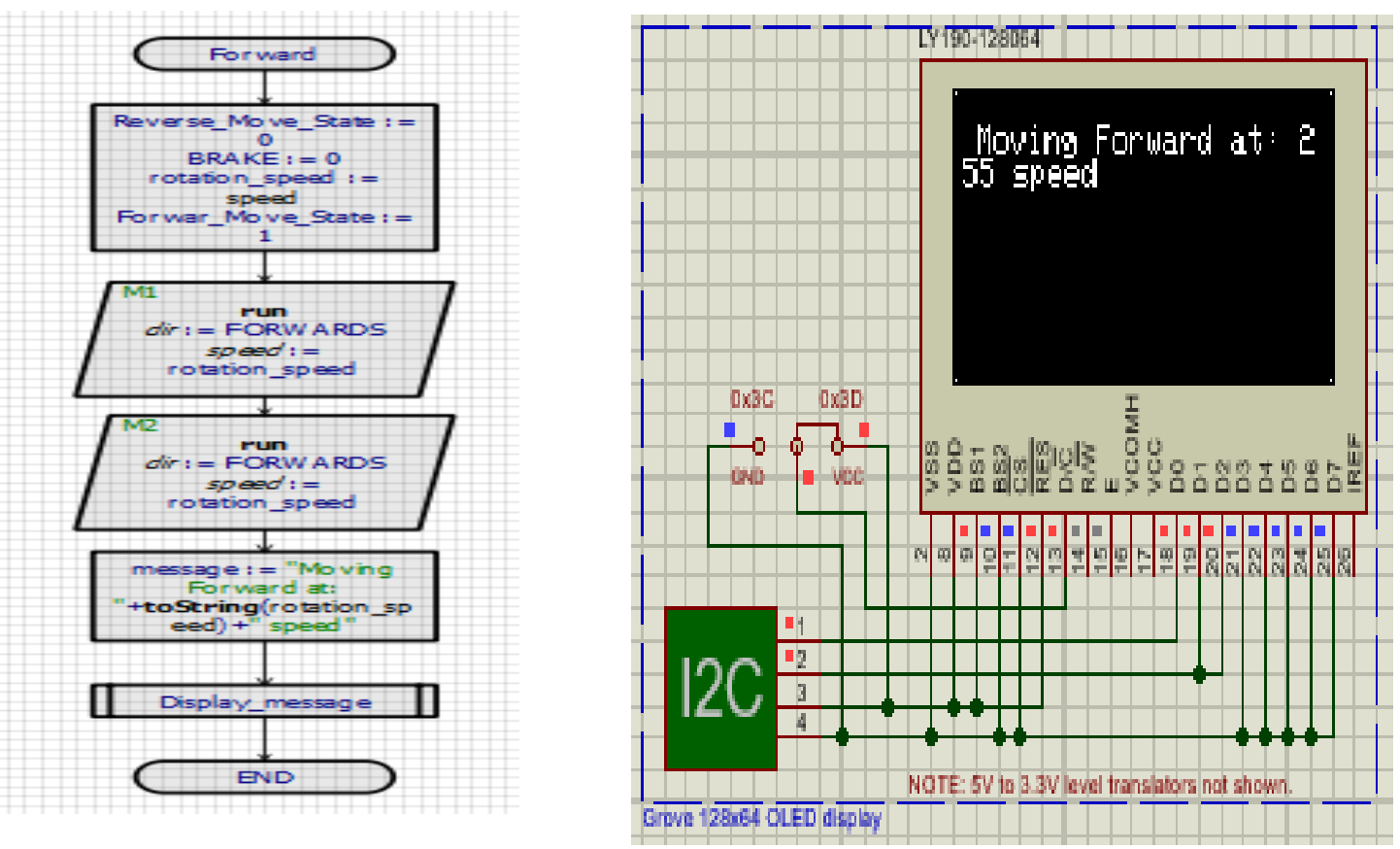

Figure 08: Forward Function.

H. Brake: A vehicle needs brakes to drive. Else it is difficult to stop in a crisis while driving. Additionally, here we have utilized a switch in the schematic outline as the brake work of the vehicle. Presently the brake work has been made in the flowchart of the visual plan. In the wake of making the brake work, a capacity is appointed were forward and switch off yet brake work on. Pins 8 and 9 of the Arduino Super will presently be relegated in the stream outline, where the advanced right is valid. Then, at that point, the message capacity will be utilized where the message will say "Brake on". Squeezing the brake switch on the schematic outline will show the message on the presentation and the vehicle will stop. The framework is displayed in the accompanying figure 9. 

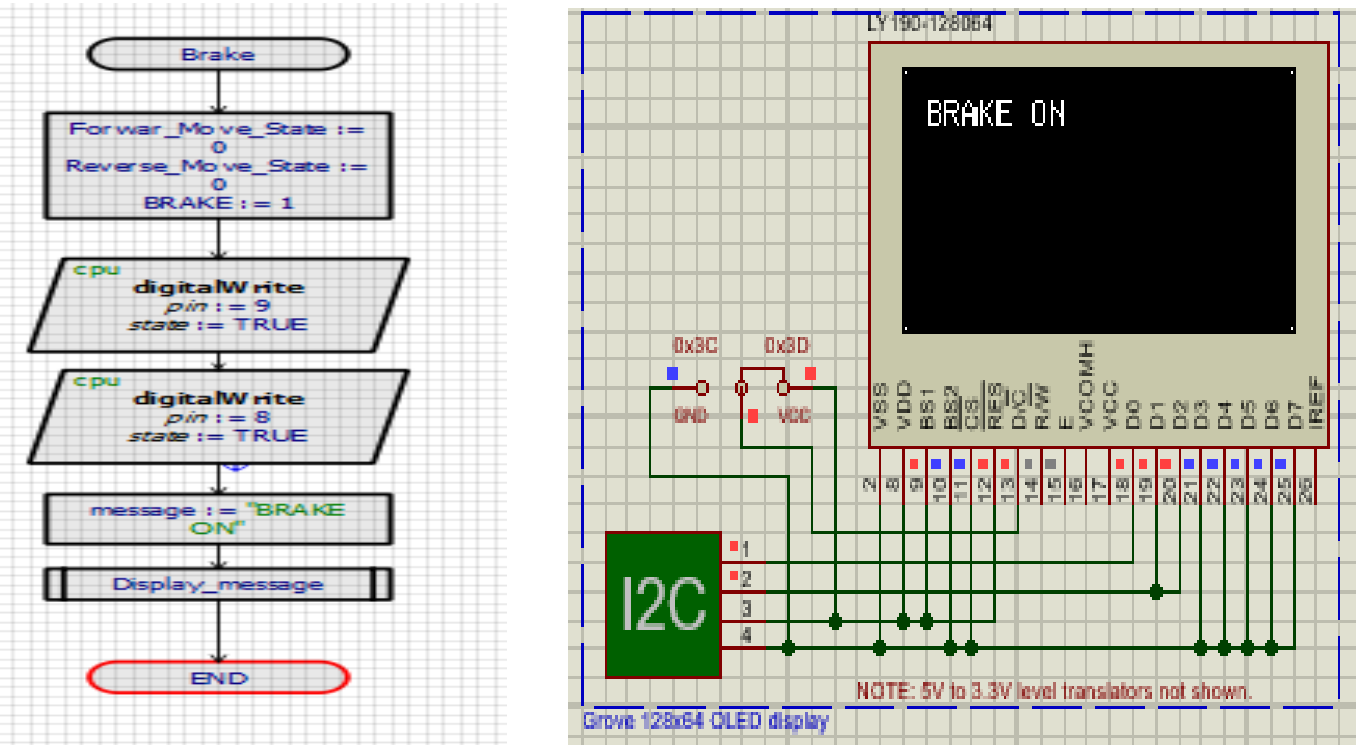

Figure 09: Brake Function.

I. Reverse: On the off chance that a vehicle has forward work, it should have the opposite work. This time a converse capacity has been made in the vehicle to run backward. Initial a capacity is doled out, which incorporates forward and brake work off yet turn speed and converse speed on. Pivot speed can be taken from 0 to 255 here, we have utilized 255 for turn-around speed here. Then, at that point, we dole out the run capacity of engine 1 and engine 2 where bearing and speed pivot are doing speed show. At the point when we divert on the forward change from the schematic graph, our presentation message will show the moving opposite and how quickly it is moving. Since we have utilized Speed 255, it will show 255 here, as displayed in Figure 10 underneath.
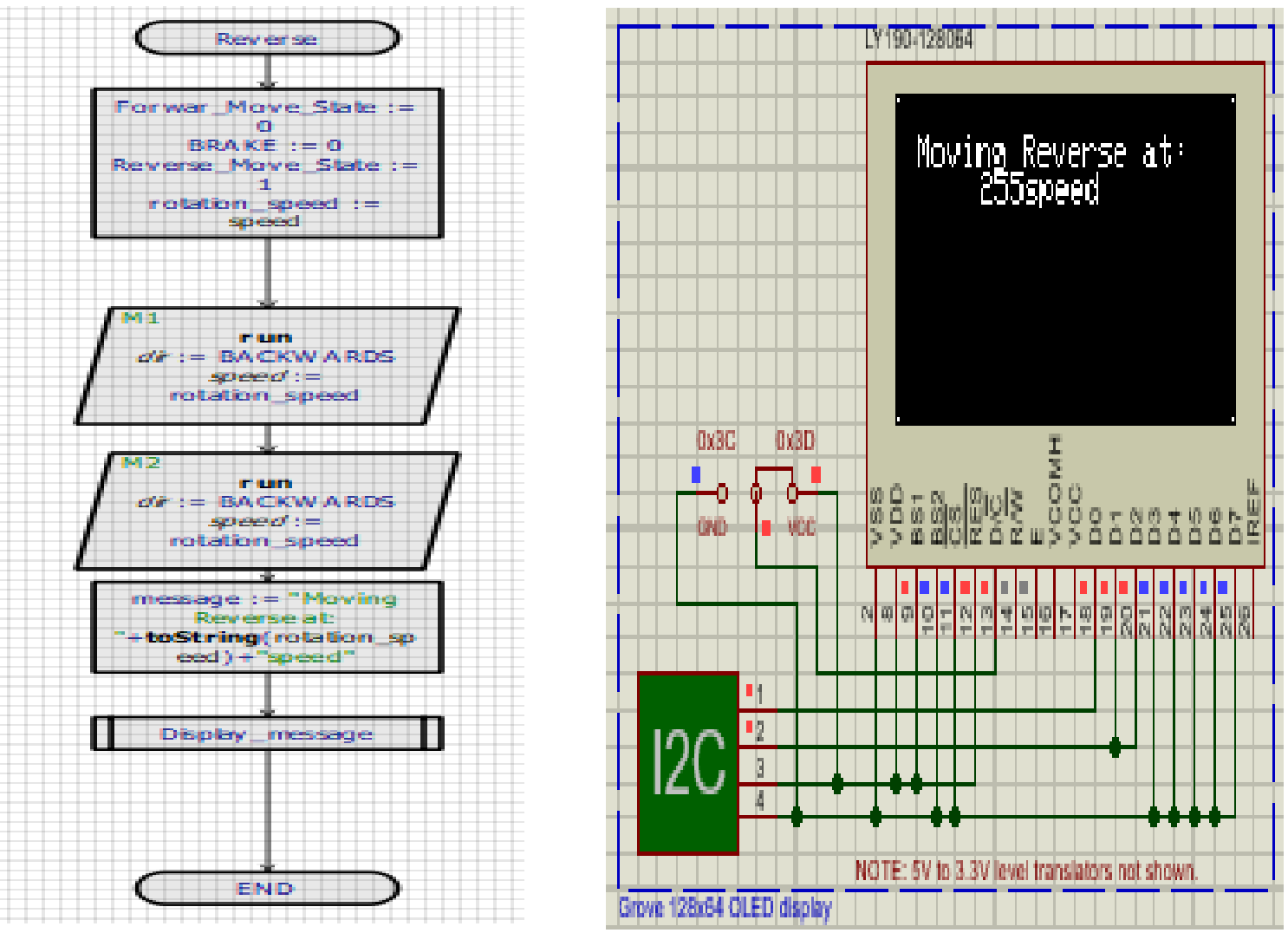

Figure 10: Reverse Function. 
J. Move Right: Then, at that point, the move right capacity is made. Where in the schematic graph, if you move the right switch on, the vehicle will go to the right side. All things considered, a capacity will be allocated in the capacity stream graph. The right move in the middle of the capacity will be on just the rest forward, brake, and opposite capacity will be off. Forward will be on possibly to go to the right side and to assume it is for the opposite. The converse will be on. At the point when the move right switches are turned on, the showcase will show "Slowing Down" in the message and allot pins 8 and 9 of the Arduino Mega in the stream graph, where the advanced right is valid. Then, at that point in the stream graph, 4 seconds will be allocated to the arrangement. After the arrangement Pins 8 and 9 of Arduino Uber will be appointed, where the computerized right is bogus. At the point when the vehicle goes to the right side, its turn speed will show 80 . What is more, the presentation message will show "Ready to turn right". Figure 11 shows this.
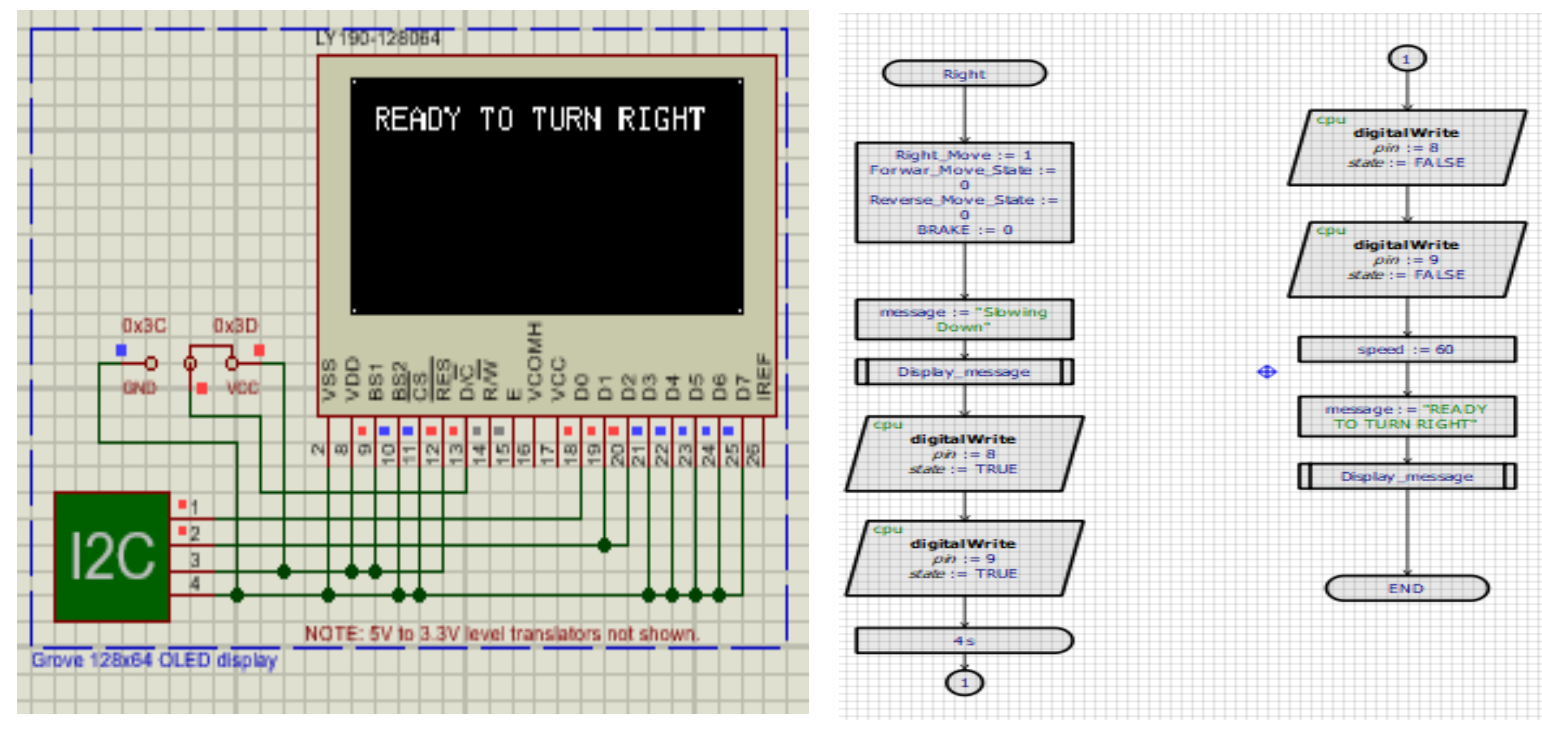

Figure 11: Move Right Function.

K. Move Left: Move directly just as move left capacity has been made. Where in the schematic chart, on the off chance that you move the left switch on, the vehicle will go to the right side. All things considered, a capacity will be appointed in the capacity stream diagram, the left developments in the capacity will be just one, the rest will be forward, brake, and opposite work off. Forward will be on possibly to go to one side and assuming it is for converse. The opposite will be on. At the point when the move left switch is turned on, the presentation will show "Slowing Down" in the message and appoint pins 8 and 9 of the Arduino Mega in the stream diagram, where the advanced right is valid. Then, at that point in the stream outline, 4 seconds will be allocated to the arrangement, after the arrangement Pins 8 and 9 of Arduino Uber will be allocated, where the computerized right is bogus. At the point when the vehicle goes to one side, its turn speed will show 80. Furthermore, the presentation message will show "Ready to turn left". Figure 12 shows this.
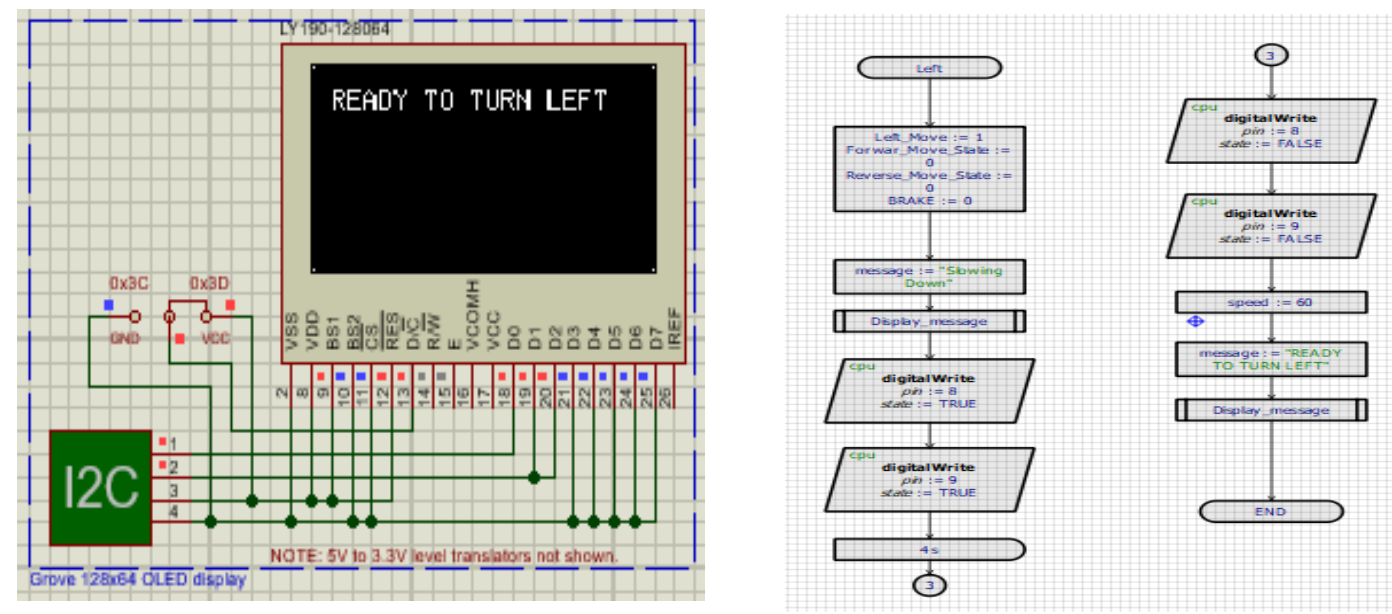

Figure 12: Move Left Function. 
J. Led: Driven lights are vital materials for a vehicle. Lights are required for night traffic. Outlandish at evening time to move to start with one spot then onto the next without lights. That is the reason we have made a Driven capacity stream outline here toward the start of which a capacity is allocated where start and LEDs are on. When turned on from the schematic graph, The Drove will turn on and the presentation will show "LED is turn on". It is displayed with the assistance of Figure 13.
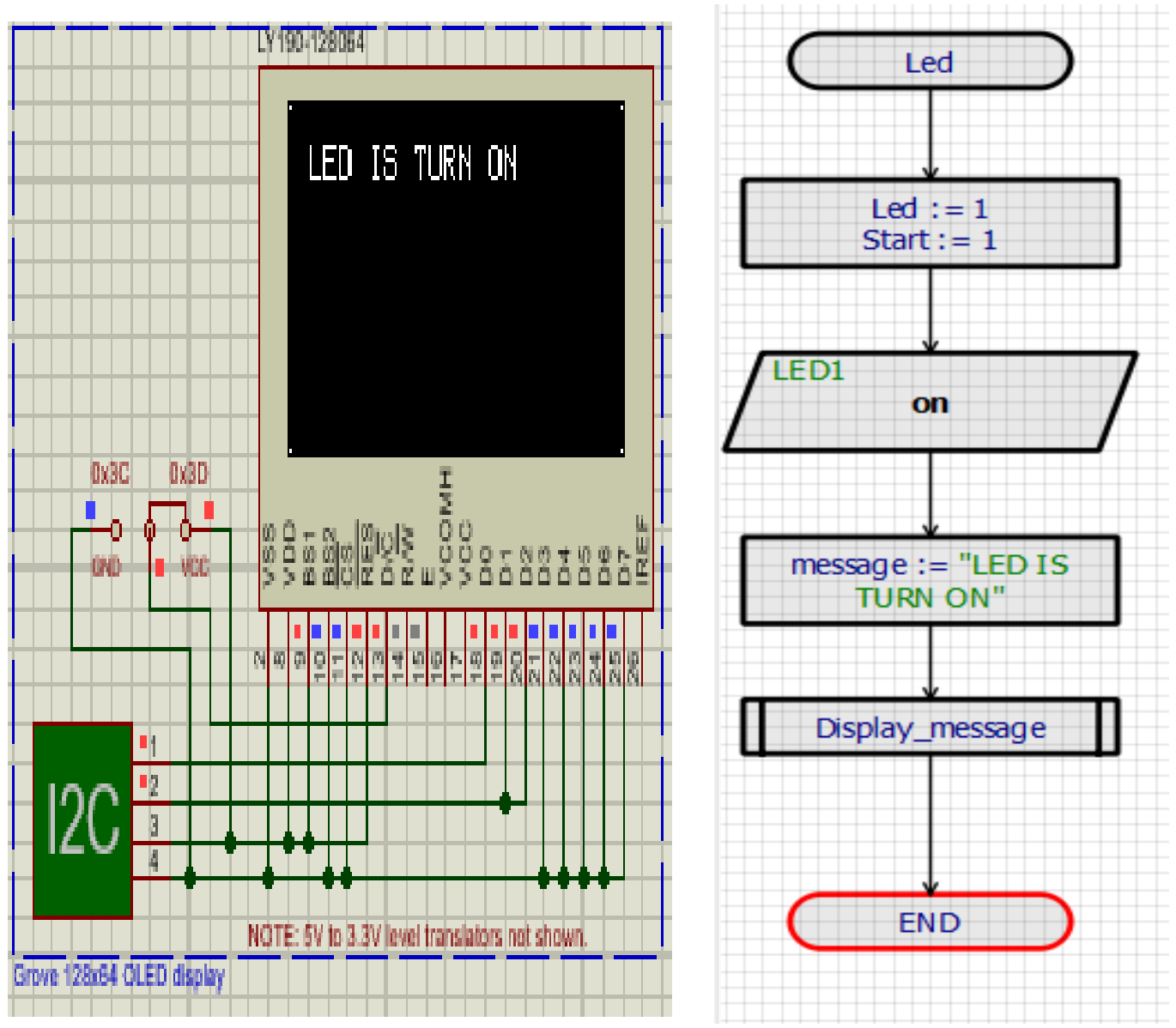

Figure 13: LED Function.

K. Horn: The interest for lights just as horns in vehicles isn't less. At the point when a vehicle is moving, horns are required in various circumstances, like surpassing a vehicle, when something unexpectedly goes off the street, etc. Here is a utilitarian stream diagram for the horn, where the horn and start will be on. At the point when the horn is turned on from the schematic outline, the horn will sound and the showcasing message will show "horn on". Presently a 3-second postponement has been utilized. Following 3 seconds the horn will stop alone and show "Horn off" in the presentation message. It is made apparent with the assistance of Figure 14. 

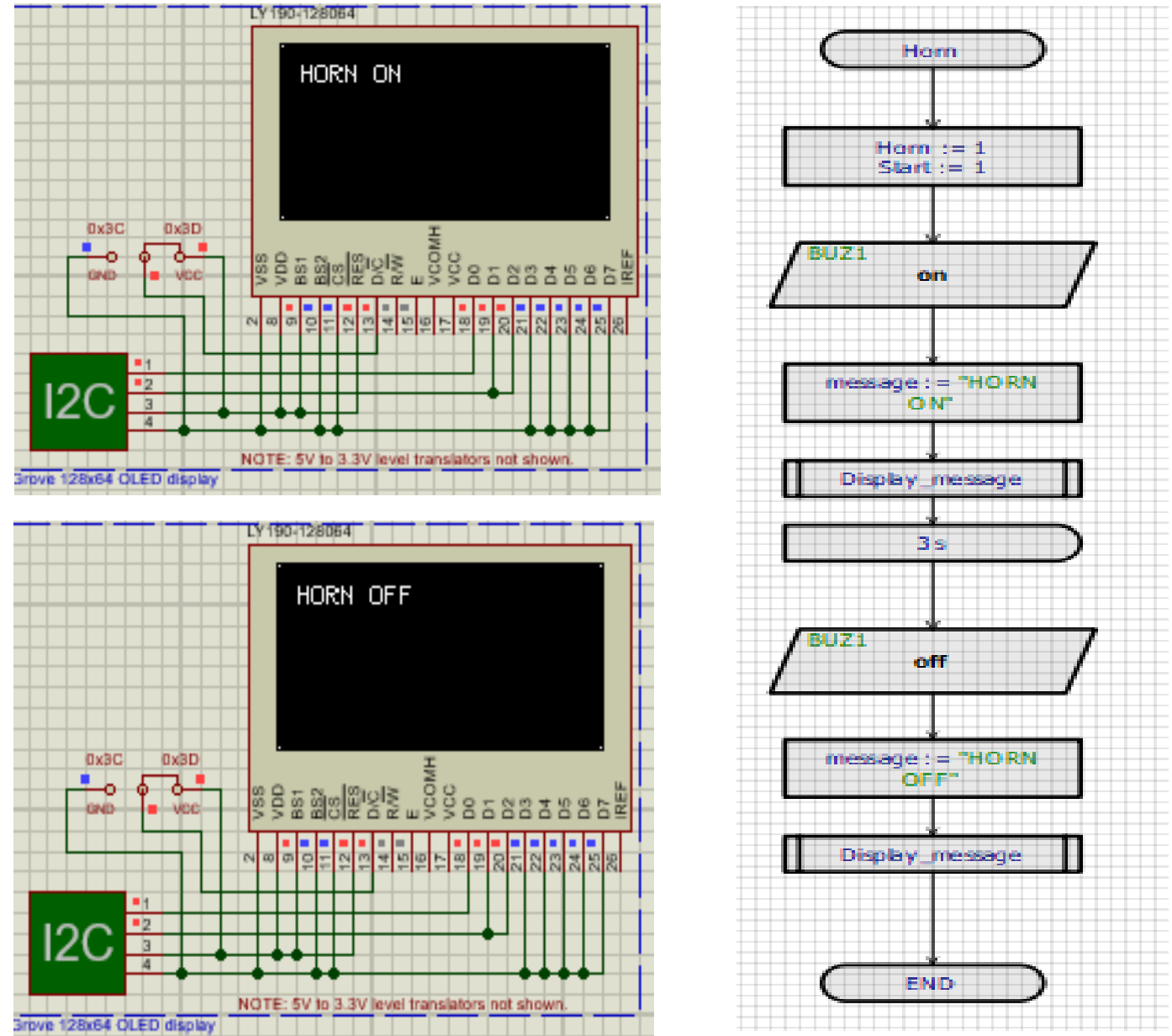

Figure 14: Horn Function.

\subsection{Working Mechanism}

This framework is assembled totally with reenactment programming proteus. Initial, a schematic graph is made, then, at that point through a visual originator, a flowchart of capacities needed for a vehicle is made. It is made with the assistance of Arduino Mega, with an engine safeguard, OLED show, switch, LEDs appended. When the reenactment is turned on, the vehicle selfdiscipline is on, and the presentation will show "Welcome on board". In the wake of turning on the beginning switch, the showcase will show "Engine ready to start" and following a four-second arrangement, the motor will turn over and the presentation will show "Engine start". Presently if the forward switch is turned on, the vehicle will keep on pushing ahead at 255 pivot speeds. Again, if the brake switch is turned on the vehicle will stop and the showcase will show "brake on". At the point when the converse switch is turned on, the vehicle will keep on moving in reverse at 255 pivot speeds. Presently assuming the vehicle's move right or move left switch is turned on, the vehicle will go to one side or left at 60 pivot speed. Presently turning on the vehicle's LEDs will illuminate and assist you with driving around evening time. At the point when the horn is turned on, the sound will stop again following three seconds. Presently every vehicle can be begun however it should be halted. Presently if we switch on the stop the vehicle will stop and the presentation will show "Engine stop". An electric vehicle requires a decent battery. If the battery doesn't give great assistance, the vehicle won't give great help.

\section{Results and Discussion}

Electric vehicles are viewed as a compelling answer for decrease ozone-depleting substance outflows. Regardless of broad investigations the elements and qualities of electric vehicles and their charging framework plan, advancement, and organization displaying of electric vehicles are as yet developing and restricted. This article gives a thorough audit of electric vehicle examines and distinguishes existing examination holes in parts of hypothesis, demonstrating techniques, arrangement calculations, and applications. This article initially depicts the idea of electric vehicles, piece of the pie, includes and charging foundation. Then, at that point, concentrates with traffic task issues of electric vehicles on the organization and restricted charging offices are 
explicitly examined. We infer that consider the extraordinary electrical components of vehicles, (for example, range limits) as far as foreseeing their steering conduct and charging the framework plan.

At the point when a vehicle radiates over the top measures of smoke, almost certainly, it isn't as expected ensured or kept up with. At the point when a vehicle is ineffectively secured or kept up with, even vehicle hardware intended to control the degree of toxin discharges may not work as expected. Diesel motors normally produce four sorts of exhaust. It is displayed underneath with the assistance of Table 1.

Table 1 - Checking the smoke tone and what is implied by these

\begin{tabular}{|c|l|}
\hline Black Smoke & $\begin{array}{l}\text { Black smoke charging is typically a sign that the fuel-air proportion in your motor is extremely rich. } \\
\text { This implies that the fuel injectors are either adding an excess of fuel or the admission valves is not } \\
\text { permitting sufficient air to enter. (Kumar et al., 2018) }\end{array}$ \\
\hline Bluish Smoke & $\begin{array}{l}\text { Although it is effectively confused with bluish smoke, that has a blue tone can mean something other } \\
\text { than what's expected. Typically, this issue is brought about by a motor that consumes a lot of } \\
\text { oil.(Artmeier et al., 2010) }\end{array}$ \\
\hline $\begin{array}{c}\text { White or Grey } \\
\text { Smoke }\end{array}$ & $\begin{array}{l}\text { However, on the off chance that the white release is terminated and doesn't disappear, you have a } \\
\text { more concerning issue on your hands. This is normally because of coolant spills in at least one burning } \\
\text { chamber.(Artmeier et al., 2010) }\end{array}$ \\
\hline White Steam & $\begin{array}{l}\text { The discharges you see are not smoke by any means, yet steam. Provided that this is true, see yourself } \\
\text { as fortunate! Steam is normally nothing to stress over. This frequently happens when the tail gathers in } \\
\text { the line while your vehicle is left. This is a typical event in the Pacific Northwest winter.(Artmeier et al., } \\
\text { 2010) }\end{array}$ \\
\hline
\end{tabular}

These exhausts joined with air, increment the measure of carbon dioxide noticeable all around and, when joined with human breath, cause different lung infections. S builds the measure of carbon dioxide noticeable all around when blended in with air and causes different illnesses of the lungs when blended in with the human breath. Because of this smoke, an individual is tainted with a cellular breakdown in the lungs, COPD (ongoing obstructive aspiratory illness), coronary illness, stroke, asthma, conceptive impacts in ladies, untimely low birth weight children, and so forth

If we talk about fossil fuel byproducts, energy effectiveness, commotion contamination, and air quality, EVs are the immediate victor. Be that as it may, in case we are discussing force or starting value, diesel-motor vehicles will win(Brito et al., 2013). Although diesel vehicles are the primary poisons, it should be recalled that a few segments of EVs can be awful for the climate, particularly for their batteries.

Although diesel and EV motors enjoy their benefits and weaknesses, the decision regularly relies upon the individual inclination and useful prerequisites from the purchaser. Notwithstanding, government intercession is making it harder to make a few kinds of diesel vehicles. In the following decade, 24 European urban communities with an absolute populace of $60+$ million will boycott diesel vehicles. An enormous number of nations, including France and China, are seeking after the situation. It very well may be pricey to proceed with the creation and utilization of diesel vehicles. As per the U.S. Division of Energy's Office of Energy Productivity and Environmentally friendly power, "About 59\% - 62\% of the electrical energy from the EV matrix is changed over to power in the driver's seat. Customary fuel vehicles convert about $17 \%$ to $21 \%$ of the energy put away in gas into power on wheels. It is assessed that $85 \%$ to $90 \%$ of the power is conveyed and put away in an EV battery is utilized by the vehicle's electric engine. At the end of the day, up to $90 \%$ of the energy delivered is utilized in cars (Rajan \& Raju, 2019). Working and support costs are accessible when changing from diesel to power. On the functional front, end clients should consider the cost of diesel fuel. It is costly and can stay up with rising worldwide interest. Figure 15 shows that running an electric motor is more affordable than running a diesel. That was not the situation in 1992, yet circumstances are different. The economy of water system siphoning is agreeable to electric engines(Brito et al., 2013). Figure 15, A large number of all-out yearly expenses of working 1,500 hours of 75 -pull water system siphons each year utilizing electric engines or diesel motors. 


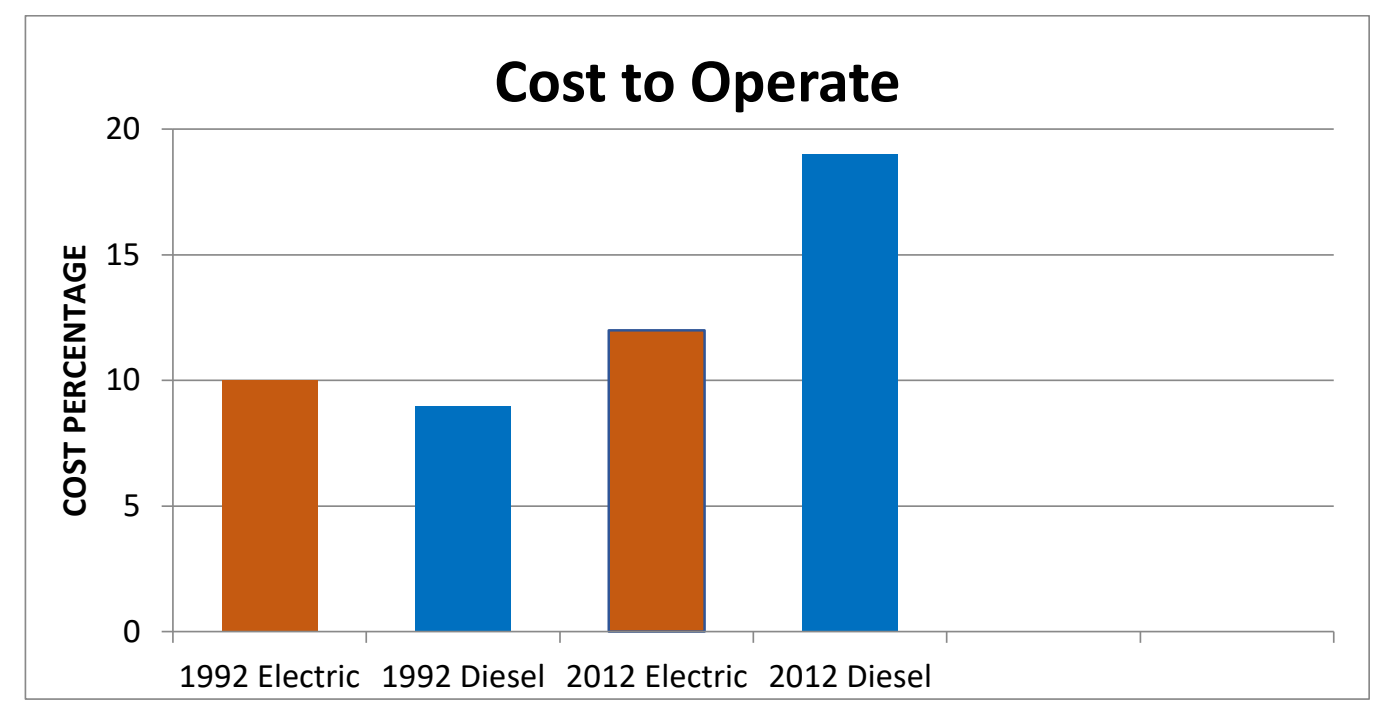

Figure 15: Cost to operate chart.

The attributes of both electric and diesel vehicles are introduced in Table 2. The EV is longer than a diesel vehicle, with the goal that the boot can make up for the additional room required for the battery. Renault has tradable batteries, which implies that the batteries that should be stuffed in a "container" ought to be effortlessly supplanted by a framework like the one offered by the organization Better place. The batteries are put between the rearward sitting arrangement and the boot, a critical boot "plundering" space.

Table 2- Characteristics of Electric Vehicle (EV) and Diesel vehicle

\begin{tabular}{|c|c|c|}
\hline Characteristics & EV & Diesel Car \\
\hline Vehicle mass $(\mathrm{kg})$ & 1605 & $4559 \times 1804 \times 1469$ \\
\hline Dimensions $(\mathrm{mm})$ & $4748 \times 2041 \times 1458$ & 77 \\
\hline Engine Type & Synchronous Motor Rotor Winding & Turbocharged Diesel common-rail \\
\hline Power $(\mathrm{kW})$ & 70 & 6 speed \\
\hline Gear Box & Direct drive (1 speed) & Diesel fuel \\
\hline Storage Energy Type & Lithium-ion battery & 701.4 \\
\hline Stored Energy $(\mathrm{kWh})$ & 22 & 1363 (combined) \\
\hline Range $(\mathrm{km})$ & 185 & 190 \\
\hline Maximum Speed $(\mathrm{km} / \mathrm{h})$ & 135 & 11.9 \\
\hline Acceleration 0-100 km/h $(\mathrm{s})$ & 13.7 & 4.5 \\
\hline Rated Fuel consumption $(\mathrm{L} / 100 \mathrm{~km})$ & - & 120 \\
\hline Rated Carbon dioxide emissions $(\mathrm{g} / \mathrm{km})$ & - & \\
\hline
\end{tabular}

As can be seen from the above qualities, the heaviness of electric vehicles is more than that of diesel vehicles. The motor sort of the electric vehicle is the coordinated engine for which the gearbox of the vehicle is utilized. Diesel vehicles, then again, utilize a turbocharged motor with six gearboxes. As it has been seen that there is as of now an absence of genuine correlations with the force utilization of electric vehicles (EVs) and diesel vehicles, the test program to survey this issue was imagined and finished.

\section{Conclusion}

This electric vehicle framework will be extremely useful in diminishing the advantages and expenses for the flow individuals. This framework can be utilized in any condition and district. With the assistance of this electric vehicle, we will want to diminish the measure of carbon dioxide in the country. With this, we will diminish our utilization of fuel oil. It is not feasible for each individual to drive and comprehend a diesel motor vehicle yet with the assistance of an electric vehicle, an individual will want to drive it without any problem. 


\section{References}

[1] Artmeier, A., Haselmayr, J., Leucker, M., \& Sachenbacher, M. (2010). The Shortest Path Problem Revisited: Optimal Routing for Electric Vehicles (p. 316). https://doi.org/10.1007/978-3-642-16111-7_35

[2] Brito, F., Martins, J. G., Pedrosa, D., Monteiro, V., \& Afonso, J. (2013). Real-life comparison between diesel and electric car energy consumption. Undefined. https://www.semanticscholar.org/paper/Real-life-comparison-between-diesel-and-electric-BritoMartins/c3d2ffedb65a0332d67aec59762a8bc801713c70

[3] Cheng, K. W. E. (2009). Recent development on electric vehicles. In 2009 3rd International Conference on Power Electronics Systems and Applications, PESA 2009 (p. 5).

[4] Hacker, F., Harthan, R., Matthes, F., \& Zimmer, W. (2009). Environmental impacts and impact on the electricity market of a large scale introduction of electric cars in Europe: Critical review of literature. 2009/4. https://trid.trb.org/view/1149618

[5] Kumar, D. M. A. R., V, M., M, N., K, N., V, N., \& Deesh, G. A. (2018). Measurement of Black Smoke in Transport Vehicle for Corrective Action. International Journal of Engineering Research \& Technology, 5(14). https://www.jjert.org/research/measurement-of-black-smoke-intransport-vehicle-for-corrective-action-IJERTCONV5IS14006.pdf, https://www.ijert.org/measurement-of-black-smoke-in-transport-vehiclefor-corrective-action

[6] Rajan, D., \& Raju, S. P. (2019). Development of an Electric Vehicle Using PWM Control Technique. 06(08), 4.

[7] Romm, J. (2006). The car and fuel of the future. Energy Policy, 34(17), 2609-2614. https://doi.org/10.1016/j.enpol.2005.06.025

[8] Sarkar, A., Sultana, S., Paul, A., \& Rashid, M. (2018). Study on Ultra-Wideband (UWB) System and Its Applications. 8.

[9] Studies, J. of C. S. and T. (2020). Automated Traffic Detection System Based on Image Processing | Journal of Computer Science and Technology Studies. https://al-kindipublisher.com/index.php/jcsts/article/view/68

[10] Yoo, H.-J., Sul, S., Park, Y., \& Jeong, J. (2008). System Integration and Power-Flow Management for a Series Hybrid Electric Vehicle Using Supercapacitors and Batteries. IEEE Transactions on Industry Applications. https://doi.org/10.1109/TIA.2007.912749 